\title{
A focus group study of Ontario dairy producer perspectives on neonatal care of male and female calves
}

\author{
Devon J. Wilson, ${ }^{1}$ (1) Jessica A. Pempek, ${ }^{2}$ ๑ Steve M. Roche, ${ }^{1,3}$ Katherine C. Creutzinger, ${ }^{2}$ (1) \\ Samantha R. Locke, ${ }^{2}$ Gregory Habing, ${ }^{2} \odot$ Kathryn L. Proudfoot, ${ }^{4} \odot$ Kelly A. George, ${ }^{5}{ }^{\oplus}$ \\ and David L. Renaud ${ }^{1 *}$ (1) \\ ${ }^{1}$ Department of Population Medicine, University of Guelph, Guelph, ON, Canada, N1G 2W1 \\ ${ }^{2}$ Department of Veterinary Preventive Medicine, The Ohio State University, Columbus 43210 \\ ${ }^{3}$ ACER Consulting, Guelph, ON, Canada, N1G 5L3 \\ ${ }^{4}$ Departments of Health Management and Companion Animals, Atlantic Veterinary College, University of Prince Edward Island, Charlottetown, PE, \\ Canada, C1A 4P3 \\ ${ }^{5}$ Department of Animal Sciences, The Ohio State University, Columbus 43210
}

\begin{abstract}
Providing optimal calf care remains a challenge on many dairy farms and has important implications for the future health, welfare, and productivity of male and female calves. Recent research suggests that male dairy calves receive a lower quality of care early in life than female calves, but further investigation is required to determine the factors that influence this disparity. The objectives of this study were to understand dairy producer perspectives on neonatal calf care practices and explore differences between male and female calf care. Overall, 23 dairy producers in Ontario, Canada, participated in 4 focus groups about calf care practices that were recorded and evaluated qualitatively using thematic analysis. Major barriers for good calf care included lack of knowledge about the best management practices for calf care and the prioritization of farm resources toward the milking herd. Some producers also noted that farm infrastructure (particularly during challenging weather) and employee training were important limitations. The economic cost of providing good neonatal calf care was important primarily for male calves and acted as a motivation or a barrier depending on the producer's beliefs about calf care and how they chose to market their calves. The primary source of knowledge producers used to develop calf care practices was their own experience, although many also relied on dairy-industry advisors, most often veterinarians. Producers were motivated by social norms, along with intrinsic pride and obligation to provide good calf care, and these motives were influenced by their emotional state. Producers expressed beliefs about which aspects
\end{abstract}

Received August 22, 2020.

Accepted December 29, 2020.

*Corresponding author: renaudd@uoguelph.ca of calf care are most important-notably colostrum management - and appreciated simple and economical solutions to calf-rearing challenges. Calf care practices were varied, and we identified a diversity of knowledge, motivations, and barriers to adopting best management practices, which sometimes differed between male and female calves. Some producers said that they did not know what happened to their male calves after they left the farm and tended to prioritize the care of female over male calves in subtle ways, such as less timely provision of colostrum. The infrastructure investment and other costs associated with caring for male calves often limited their care, but producers were still motivated to provide adequate care for male calves. These findings represent potential targets for additional research and intervention strategies to improve calf care practices on dairy farms.

Key words: male dairy calf, qualitative, neonatal calf care, focus group

\section{INTRODUCTION}

Providing optimal calf care remains a challenge on dairy farms and can lead to high levels of morbidity and mortality (Mee, 2013). Both female and male calves can suffer from suboptimal neonatal care, but male dairy calves may be affected more frequently. Recent studies have found male calves receive lower volumes of colostrum (Renaud et al., 2020) and are more likely to receive colostrum with bacterial contamination (Fecteau et al., 2002) than females. Additionally, Shivley et al. (2019) found fewer farms practiced dehorning on male calves than on female calves, and rarely reported using analgesics for the males. Because most male dairy calves in North America are sold from their farm of origin before 2 wk of age (Renaud et al., 2017) and sometimes as young as $1 \mathrm{~d}$ old (Wilson et al., 2020b), 
many of the effects of poor neonatal care are likely realized at calf-rearing facilities.

Evidence of poor neonatal calf care has been documented in male dairy calves arriving at veal facilities in Ohio (Pempek et al., 2017) and Ontario (Renaud et al., 2018c). These studies found that 35 to $47 \%$ of calves had dehydration, 13 to $14 \%$ had diarrhea, 25 to $27 \%$ had inflamed navels, and $47 \%$ had thin body condition. Suboptimal care may also be associated with dairy calves arriving at auction markets in poor condition: health abnormalities have been identified in $20 \%$ (Wilson et al., 2020c) to 43\% (Marquou et al., 2019) of calves. As a result of the effects of poor neonatal care, veal farms have reported high levels of morbidity, mortality, and antimicrobial use, which reduces animal welfare and represents a potential human health concern (Pardon et al., 2012; Lava et al., 2016). However, suboptimal calf care is likely not unique to male calves; heifer-rearing facilities have also reported high levels of morbidity associated with failure of transfer of passive immunity (Windeyer et al., 2014). Taken together, these findings suggest an urgent need to identify mechanisms to motivate dairy producers to improve neonatal calf care, particularly for male calves.

The gap in knowledge regarding producer perspectives on calf care limits the development of strategies that could motivate on-farm change. In reviewing producers' adoption of disease-control practices, Ritter et al. (2017) recommended that social science be used to understand important sociopsychological factors that influence the implementation of new strategies. For example, Bruijnis et al. (2013) evaluated dairy producers' intention to improve lameness on their farms and found driving factors (e.g., perceived urgency, knowledge about cost-effective measures) that could be used to stimulate the adoption of different management practices. Other work has found that qualitative research can be used to gain a rich understanding of dairy producer motivations and barriers (Belage et al., 2019; Roche et al., 2019) and may be a useful first step toward improvement in calf care. The focus group is an applicable qualitative research method that is ideal for the exploration of an unknown topic and can be used to assess beliefs and behaviors (Krueger and Casey, 2000). Therefore, our objective was to use focus groups to understand the barriers and motivations that influence dairy producers' calf care practices and investigate how these factors differ for male and female calves.

\section{MATERIALS AND METHODS}

This study was approved by the Research Ethics Board at the University of Guelph (REB \#19-12-015), Ontario, Canada. Written, informed consent was pro- vided by all participants. The Standards for Reporting Qualitative Research guideline was used as the standard for reporting in this paper (O'Brien et al., 2014).

\section{Study Design}

A critical realist paradigm was adopted for this study, which acknowledges that producers have a discernable perspective on calf care that is influenced by internal and external contexts. This allowed us to explore dairy producers' experiences and perspectives in light of the context of their lives and businesses that influenced these perspectives. Focus groups were chosen because of their strength in exploring an unknown topic, eliciting a large range of views, and evaluating behaviors and beliefs (Krueger and Casey, 2000). Focus group studies have recently provided insight into veterinary perspectives on calf welfare (Sumner and von Keyserlingk, 2018) and established factors that affect dairy producers' receptivity to welfare advice (Croyle et al., 2019). Furthermore, the understanding of producer perspectives gained from qualitative analysis is helpful for developing successful management strategies for disease control (Ritter et al., 2017). Therefore, the outcome of this study was expected to reveal aspects of producers' experiences and perspectives on calf care that could inform future research or extension efforts to improve health and welfare outcomes for male and female dairy calves.

\section{Reflexivity}

The research team was experienced in conducting health and welfare research with dairy cattle and included 2 social scientists ( $\mathrm{SR}, \mathrm{KG}$ ) with experience in qualitative data analysis. The first author was informed by her training in veterinary medicine and experience researching male dairy calf health and welfare. She was therefore familiar with common challenges in calf care, but less familiar with the related producer perspectives. Her background and training were not known to the focus group participants beyond the fact that she was employed as a research student at the University of Guelph. Reflexivity was established through discussion with co-authors about assumptions or biases identified during analysis and manuscript preparation, and through the maintenance of a research log containing rationales for decision-making during data analysis and interpretation.

\section{Focus Group Discussions}

Focus group sessions with dairy producers were conducted between February and March 2020. Before the 
focus group session started, producers filled out a short written survey indicating their age, their role on the farm, the size of their milking herd, and the number of calves under their care. Producers were then reminded that the goal of the meeting was to discuss newborn care practices for all groups of calves on their farm, including whether differences occurred between females and males, or among different breeds of cattle. Moderators $(\mathrm{n}=3$, due to the need to schedule focus groups in a narrow time span) trained in qualitative study methodology facilitated the focus groups, along with an assistant who took notes related to group dynamics and participant body language. Two of the moderators conducted 1 focus group each, and a third conducted 2 groups. The moderators met before the focus group to discuss the research questions and followed the same semi-structured discussion guide (Appendix 1). The guide was developed collaboratively to prompt discussion about different calf management practices related to colostrum and milk feeding, housing, and health care. Additional questions explored which calf care practices were considered most important and challenging, and aimed to determine if and why differences in care existed between male and female calves. The discussion guide was pre-tested using a group of dairy-production faculty and students attending The Ohio State University, and pre-testing prompted minimal revisions other than additional follow-up questions on the disease treatment of male calves before marketing. Audio recordings of the discussions were made, and field notes were kept by the assistant to aid in data interpretation. Recordings were approximately $90 \mathrm{~min}$ long; 2 were transcribed verbatim by the first author, and 2 were transcribed by a professional service. All 4 were checked against the original audio files for accuracy by the first author. Each of the participants and the moderator were given unique numerical identifiers in the transcripts and were deidentified for data storage.

\section{Participants}

Dairy farm owners or employees who were involved in newborn calf care on farms in Ontario, Canada, with at least 50 lactating dairy cattle were eligible for inclusion. We made no attempt to purposively sample for a balance of sexes, ages, or other producer criteria. Recruitment was initiated with an advertisement in a provincial dairy producer magazine (The Milk Producer), which is distributed online and via post to all dairy producers in Ontario. Further recruitment was conducted using purposive sampling through dairy veterinarians to identify potential focus group participants. Veterinarians were contacted via email and telephone and then distrib- uted recruitment materials to potential participants. Snowball recruitment was also used, where confirmed participants were invited to reach out to other dairy producers who might be interested in participating in the focus groups. Six to 10 participants were targeted for each group.

\section{Data Analysis}

A contextualist method of thematic analysis was used to determine the important themes in the transcripts; this method was chosen given its accessibility and strength in allowing data to be summarized and discovering unexpected insights (Braun and Clarke, 2006). To begin, the first (DW) and second (JP) authors familiarized themselves with the data through repeated reading of the transcripts and listening to the audio files. Using NVivo (version 12.6; QSR International), both authors coded 1 focus group (focus group 1) line by line, and a preliminary codebook was developed and revised collaboratively with input from social scientists who had experience in thematic analysis (SR, KC). The initial codebook included a label, a descriptive definition, and exemplary quotations from the data (Appendix 2 Table A1). Codes were collated into preliminary themes. This codebook was then used by the first author to code the remaining focus groups and revised to include new findings. The revised codebook was reviewed and finalized with SR and JP, and was then used by the first author to re-code the focus groups to ensure codes were applied consistently. Because we used multiple researchers, we chose repeated coding and maintenance of a rigorous research log during data analysis to ensure interpretive validity, rather than an inter-rater reliability metric (McDonald et al., 2019).

After coding, relationships between codes were explored and a thematic map was created by the first author (Figure 1). The results are presented with emphasis on capturing a broad description of the data rather than a detailed description of each theme (Braun and Clarke, 2006). An inductive, data-driven approach was used to develop initial themes and subthemes. The resulting themes and their relationships were then considered from a deductive standpoint, informed by literature on motivations and barriers to other farm practices (McAloon et al., 2017; Sumner et al., 2018; Roche et al., 2019), to situate our work within the existing body of knowledge on this topic. Verbatim quotations are reported as exemplars of the type of excerpt that fell into each sub-theme, with clarifying text in square brackets; verbal tics or false starts (e.g., "like," "yeah, um") were removed and replaced with ellipses. Relationships between comments from 


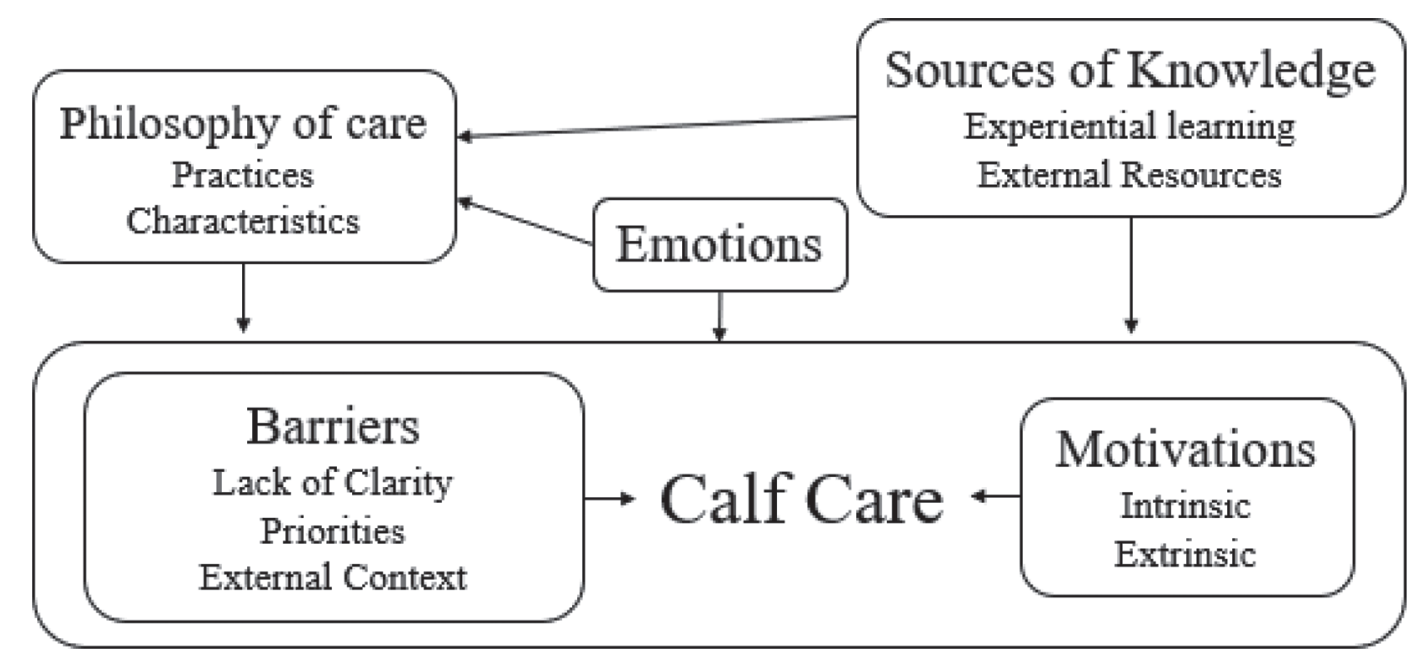

Figure 1. Thematic map produced from analysis of qualitative data on neonatal calf care practices from 4 focus groups conducted with 23 dairy producers from February to March 2020 in Ontario, Canada.

individual producers on the different calf care topics were not explored, so we did not identify the speakers in exemplar quotations. Quotations were chosen from all groups, and 11 to 22 quotes were used per group.

\section{RESULTS}

Focus groups consisted of 5 to 7 dairy producers, and 23 producers participated in total. Two groups were limited to 5 participants because of cancellations related to scheduling conflicts. Fourteen producers described themselves as farm owners and 9 as employees/ herdsmen. All participants were directly involved in the care of calves. Thirteen participants were female and 10 were male, and both sexes were represented in all groups. The median (range) age of the producers was 32 y (21 to 59). Farms were located in Southern Ontario, where producers operate under the Canadian dairy quota system, and the median (range) number of lactating and dry cows was 125 (59 to 600) and preweaned calves was 18 ( 5 to 80 ). Price data for veal calves over the period when we conducted the focus groups is limited to a range, but the Veal Farmers of Ontario reported that calves of medium to high quality sold from $\$ 70$ to $\$ 240$ (Veal Farmers of Ontario, 2020).

The results of the thematic analysis are summarized in Figure 1, which depicts 5 main themes and their relationships. Two themes (barriers and motivations) were directly related to calf care practices, and 3 themes (philosophy of care, sources of knowledge, and emotions) had an indirect influence. Because emotions were less frequently discussed, this theme is presented when emotional state most obviously affected other themes.

\section{Theme 1: Barriers to Calf Care}

Lack of Clarity. In discussing calf management, producers posed questions to one another about how they approached different aspects of calf care, including milk feeding and colostrum management in the first days of life, along with how to prevent navel infections, pneumonia, and diarrhea. The questions posed by the producers suggested uncertainty about their current practice and were frequently about how to practically accomplish a known best practice. For example, the best methods for milk feeding were commonly discussed, with one producer asking, "I'm interested in feeding 3 times a day, but what is your time frame for feeding 3 times a day?" and in another group a producer asked, "I'll only ever tube once, milk once (like the first colostrum), and then after that I won't tube again. But sometimes you've got to skip a feeding to get them hungry enough to drink. So anyway, I'm just curious what you guys do." Occasionally, producers sought an answer from the group moderator; for example, regarding navel care one producer asked the moderator, "What is better, dipping or spray bottle?" A few producers also indicated a knowledge gap about male calf outcomes after the calves leave their farm: "They get treated the same as the heifers for the first 4 days of their life, and then I have no idea what happens."

Prioritization of Resources. Producers described several challenges related to how they prioritize different aspects of calf care. Tradeoffs between different calf care needs were often discussed; one producer expressed this as, "Right when the calf comes out, you do want the mother to be there to clean it up. But we know Crypto [Cryptosporidium] is in that area, so you want to move 
it. And I think it's kind of like, the hard decision between the two." Producers often conveyed the need to compromise between the care of different classes of animals and the fact that calf health may rank lower among their priorities. For example, one producer described a decline in colostrum production on their farm as having a positive effect on cow health during the transition period: "With the downtick on colostrum, the other thing we have to consider is that everything else with these fresh cows is fantastic. Like the RPs [retained placenta], and the DAs [displaced abomasum], and the ketosis is like 2\%. So do we really want to screw with anything on the dry-cow program just to get some more colostrum?" A few producers also said that care of male calves was a lower priority than care of females. For example, one producer found it stressful trying to complete the newborn care protocol in a timely fashion, stating, "I'm always like, 'Oh my gosh, I have to get colostrum into it!' Like it bothers me," and later explained "And sometimes, honestly, it doesn't work. Then I just have to put it [out of] my head. If it's a bull calf I feel a bit better." When asked to describe why bull calves were less stressful, she explained, "Well, because they're not going to be in my milking herd." Producers also frequently noted that calf care represented a significant and sometimes prohibitive workload considering all the other responsibilities of dairy farming. When speaking about finding a newborn calf, one producer suggested, "It just throws your whole day off because ... [when a] cow calves ... you can waste an hour there." Some producers also specifically singled out male calves as being additional work, with one producer saying, "Feeding a bull calf is just more extra work."

Other challenges with calf care were indirectly related to other farm priorities, such as how they managed their physical resources, including infrastructure and staff. Producers cited equipment or facility challenges as a barrier to calf health: for example, "You think you're doing everything right and you're still getting a pile of pneumonia, and there's nothing you can do about it because it's in a converted barn that just has poor ventilation." Infrastructure was sometimes specifically discussed as a limitation for keeping male calves: "We simply don't have space for bull calves." Both farm managers and employees said that training on calf care practices could be problematic. A farm employee recounted, "They just put me in and said, "Just watch what we do and do it,' and it is a little scary." In some cases, farm employees said that they had to rely on their previous experience: "It was kind of a mess when I showed up. There was no real structure, and I had experience from other farms. So, I tried to write up a protocol that was helpful for myself, but also all the other employees." When asked how training looked for their calf employees, some farm owners quickly responded with negative sentiments such as, "It's just a disaster," and, "You can't get people to care enough." However, others had a more nuanced view: "I think it depends on the interests of the person. We do have one employee that is amazing."

External Context. Producers discussed calf care challenges relating to factors beyond their control, such as the economic realities of the Canadian dairy industry and the weather. Economic considerations were mentioned infrequently relating to female calves, but cost and market limitations were commonly discussed in the context of male calves. As one producer stated, "I have to admit ... bull calves, for what we get paid, I do the best, but the extra care sometimes is not ... given to them." This was particularly problematic for a Jersey producer who euthanized male calves because they could not find a market for them: "They're not worth anything. Nobody wants them." However, some producers still felt they were able to find solutions to these challenges; for example, many producers used beef genetics when breeding their dairy herd: "We're going a lot more for like breeding with beef ... that will raise your bull calf value." When asked about the biggest challenges for rearing calves, variable weather was frequently mentioned: "I would say weather. Weather is a big one. We've got curtains on either side and we're rolling up, we're rolling down, we're rolling up, we're rolling down, just [to] keep that happy medium in there."

\section{Theme 2: Motivations for Calf Care}

Intrinsic. Producers were motivated to provide good calf care by internal factors, including social norms and a sense of pride and responsibility. For example, a discussion between 2 producers indicated a social obligation to the dairy industry to provide good male calf care: Producer 1: "I think it is a good idea that we do keep them longer. There was far too many newborn/day-old calves at the sale barn which ..." Producer 2: "With wet navels." Producer 1: "... isn't good for our industry either." The public perception of male calf treatment was also influential; one producer expressed the importance of appropriate sale practices to ensure public confidence in dairy farming, stating, "We're already looked at like barbarians, taking them away and sending them to the sale barn. At least if they're up, running around, and somewhat healthy, then it's a little better to the public than this newborn that just gets chucked in the corner of a pen." A third social influence was the producer's relationship to the calf buyer. Producers who sold their calves directly to a calf buyer generally felt it was important to maintain a good relationship with their buyer. One producer explained, "If 
they're smaller, or they're maybe not as perky, of course I'm going to keep it longer for him, because we have a relationship with him. Like ... why would I give him a sick calf?" Most producers expressed a preference for selling male calves directly off the farm, stating, for example: "If a guy wants to buy them off farm, that's ... I'll even give him a bit of a break on the sale barn price, because he's picking it up and I want to give him [the calf buyer] a chance." However, one producer preferred to sell their calves at auction because of a lack of transparency about the current market value for bull calves when selling them privately, saying "Mine go to the sale barn simply for simplicity's sake, I guess. I did have a short period of time where ... one guy was picking them up, and my biggest thing was I don't know if he's actually paying me enough."

Beyond their social normative beliefs, producers also described providing good care to male calves as a moral endeavor: "I think, morally, it's more so that you treat them the same, because I don't want to see a bull calf die or suffer." Similarly, another producer associated male calf care with his professional obligations, stating, "It's a living creature and ... my job is to take care of my cattle, so I'm going to take care of it." Producers also described a strong intrinsic motivation to ensure that their calves remained healthy. This was sometimes related to the workload associated with calfhood disease treatment; one producer stated, "Yeah, as much time as the first couple days takes, scours can take a ton of time, too. So there is motivation to put the effort in." Another producer emphasized that care of female calves was especially important to ensure they became a successful herd member: "We do the best we can, but focus on what we're supposed to make money on. That's our dairy milkers ... make sure our heifers are right." For male calves, producers were instead motivated to provide good care to ensure that they could sell a healthy calf. As one producer stated, "If it doesn't get the colostrum it's going to get sick, and then I can't sell it anyways." Others also hoped their males would be successful at veal farms, with one producer stating, "And the bull calves, as far as it's ethical, just make sure we raise a good bull calf for a week so the next guy who's trying to raise it has a chance."

Producer emotional state was infrequently discussed but seemed to play a diverse role in calf care; producers relayed how feelings of satisfaction or guilt influenced their management practices. One producer said, "Best feeling is when I have like 4 or 5 hutches clean and ready. Because then [when] I have a calf born, I can move it right away." This producer later emphasized the importance of keeping calves warm, stating, "I feel bad when I don't have coats on them." Regarding male calves, one producer said, "When you're getting like 25 or 50 bucks for a calf, it's not ... even at 100 bucks I'd challenge to say it's even worth my time," but felt he could not euthanize them due to the emotional toll, stating, "I don't have the heart to euthanize bull calves."

Extrinsic. Government regulation was influential in some aspects of calf care. One example related to the requirement of the Canadian dairy industry not to ship milk from cows for $3 \mathrm{~d}$ after parturition. This motivated one producer to give the transition milk to the newborn calves, as he stated, "I can't use the milk for 6 milkings anyway." Regarding male calves, a recent change in Canadian animal transportation regulations influenced the time male calves are required to stay on dairy farms; as one producer noted, "Ours just go to the sales barn around like 8 days-ish. I think my neighbor read some article saying that was the minimum." The most impactful regulation changes regarding calves require that calves sold through auctions must be over $8 \mathrm{~d}$ of age, and unweaned calves (those too young to eat only hay and grain) cannot be transported more than $12 \mathrm{~h}$. One producer thought these new rules would affect male calf care positively, suggesting, "If we have to keep them for 2 weeks generally, mine anyway are getting sick from 7 to 10 days old so ... we're going to try and avoid those scours," but he also expressed some frustration at this, saying, "Yeah, the unfortunate part ... a good-looking calf you send at 3 days old isn't worth any more than a 8-day-old, 10-day-old calf. So there's no benefit for us to put the extra time and money into them."

Producers were also motivated by economic capital. One producer who kept her male calves to raise for the grain-fed veal market said that neonatal calf care was economically beneficial, explaining, "Where for us we're keeping all of our animals, [so] it's a big benefit. Because we don't want to have to deal with sick calves." One producer felt that even low calf prices motivated good care, because it ensured the calf would still be saleable: "Prices are so low for calves. They [calf buyers] are pretty picky. So if they even catch the scent that that calf might be a little sick, they just leave it and they drive away without it." Some producers also expressed a preference for price consistency and suggested having a baseline price would be beneficial: "If you said there was a base of 75 bucks a calf that you had to get for a bull calf, then guys might be willing to put more effort into making sure there's colostrum and proper care."

\section{Theme 3: Sources of Knowledge}

Experiential Learning. Calf care practices were informed primarily by experiential learning, as evidenced when producers shared stories about knowledge gained from past successes and failures. A typical example 
was, "What we really found was that when we switched to making sure it got fed within an hour of being born, the amount of calves we had to tube drastically went down." Past farm experiences often motivated changes in calf care practices, as described by one producer: "All the stuff that I find that we do with our calves is just from learning otherwise. Like so we didn't use to navel dip, but then we got a whole bunch of hard navels." Producers also sometimes used data collected on their farm as a way of modifying their care practices; for example, one producer assessed air flow in the calf barn: "We did the smoke test and over the first 3 pens and the first robot pen, which is where we see the most pneumonia issues, that's where the worst ventilation is, so we need to add another tube going the opposite direction on top of the first 3 pens."

External Sources of Knowledge. Producers also used external sources of knowledge to inform their care practices, which included dairy-industry professionals such as veterinarians, calf buyers and feed salesmen, conferences or industry meetings, and their peers. Veterinarians were frequently listed as a source of information, as this producer noted: "We were told by our vet ... they can be infected with Crypto when they are younger, but it won't show until . . 5 to 8 days." Producers sometimes described how the knowledge gained from veterinarians influenced their practices: "Most of the colostrum just gets fed to our own calves. We always used to sell it, and then one vet once told me, 'You are selling your gold.'" Some producers also referenced other dairy producers' calf protocols, although those protocols did not necessarily influence their own practices. In referring to a neighbor's calf housing, one producer said, "It's in the corner of his old barn, and the ventilation is terrible. And he's got it packed, and they're always bedded really well. And he feeds tetracycline, and they're the best calves I've ever seen. I still don't do it. But his calves do great!"

\section{Theme 4: Philosophy of Calf Care}

Critical Practices. Producers believed that some calf care practices were more important than others, a belief that was emphasized throughout the discussions. When asked about the most important calf care practices, producers most frequently identified colostrum management; one producer simply stated, "Colostrum feeding. That'd be mine." Producers also brought up biosecurity; one producer explained, "That calf is born and it goes right away in 100\% clean environment." Dry-cow management was also highlighted by one producer, who said of his dry cows, "If she's been there for a while and there's lots of straw [when] she comes out, just everything's better." Last, the im- portance of disease monitoring and early treatment was underscored; one producer stated, "I think if you can manage it well and pick up on those calves ... the first little sign that they're off ... you're right on them, then it's better."

Characteristics of Good Care. Producers believed that some general characteristics of calf care were valuable. First, some producers emphasized consistency and familiarity with the calves. For example, one producer felt that having additional labor for part of only one of the calf feedings worked best: "I' $m$ doing kind of 2.5 feedings out of 3 every day, and it is a lot better for consistency that way, just because then I know exactly what everybody has done all day." Furthermore, calf care that resembled how they would be raised in nature was seen as desirable by a few producers, as exemplified in a statement about milk feeding practices: "So, trying to do as much as like, how does it go in nature ... then whenever you have a question, [you think] how would it go in nature"? Variability was noted in producer opinion on calf care protocols, because some preferred to adapt their care based on the situation of their farm or the calf, saying for example, "Yeah, we're not so ... protocol-y ... we just look at calf-by-calf." However, others thought standard protocols were preferable, stating that right after the calf is born and placed in an individual pen, "I feed it milk, it goes through that entire protocol."

Producers also frequently noted that simple solutions to calf care challenges were valuable, stating for example, "We did want to give our calves more milk, but ... it was either 3 feedings or try to find bigger bottles. The bigger bottles were a little bit easier than doing 3 feedings." Producers discussed how technology such as an automatic calf feeder could be used to simplify and improve calf care, "That is the one thing I do really like about the calf feeder is the slow weaning, and then they've got calf starter and hay there and ... I find the transition is really, really smooth." Simplicity was also emphasized for male calf care, related to how they are sold, their pricing, or having a consistent protocol for male and female calves that multiple staff can follow. For example, one producer explained, "We're treating all bulls and heifers the same primarily because we have a lot of night staff that ... if I have to explain to you the difference between how you're going to treat a bull calf and how you're going to treat a heifer calf, it's just a lot more than a lot of them are up for contemplating, so it's just, 'This is a calf. This is what you do to it every single time.' It's just a little easier." One producer also stated that feelings of frustration can motivate a change in calf management practice, as occurred when he was using robotic calf feeders, which he found challenging: "We switch(ed) back to hutches this summer and ... it's 
a lot easier. I was getting so frustrated there last year with all the disease problems."

\section{DISCUSSION}

The objectives of this study were to identify barriers and motivations that influence dairy producers' calf care practices and assess differences between male and female calves. We found that knowledge and prioritization of calf care, along with some external factors such as low prices for male calves, were important barriers to calf care. Producers were intrinsically motivated to provide good calf care by their sense of pride and morality, by social obligation to other dairy-industry stakeholders, and sometimes by the economic benefits for their herd. The barriers and motivations identified were influenced by producer's philosophies, sources of knowledge, and emotions.

The lack of clarity on how to provide the best calf care indicates a need for producer education, especially related to the frequency and methods of milk provision, and practices required to prevent and treat disease. Furthermore, their openness to asking questions suggests that producers were interested in learning from both their peers and perceived professionals (the moderator). These findings are reflected in a study by Sumner et al. (2018) in which producers noted that benchmarking reports were informative and beneficial. Despite this, the authors suggested that providing an opportunity for producers to discuss their different practices and learn from each other could have helped resolve practical considerations in implementing change. When evaluating the adoption of biosecurity protocols, Cardwell et al. (2016) also found collaborative education with veterinarians providing tailored advice for producers was effective in reducing pathogen presence. Although these studies suggest potentially effective ways of addressing the identified knowledge gap, Lam et al. (2011) noted that gaining knowledge does not always result in improved farming practices because of other motivations and limitations. Together, these studies suggest that addressing a lack of clarity on how to provide optimal calf care should make use of both professional advisors and peer learning in a collaborative way that considers how producers in their unique contexts can be motivated to accomplish this goal.

Along with identifying a need for effective education, the gap in calf care knowledge points toward an opportunity for research and potentially product development. For example, a wide range of preferences for navel-care products and application methods was reported. This is reflected in recent research, which has found minimal differences in navel infections and other comorbidities between calves for which different navel dip products were used (Wieland et al., 2017; Fordyce et al., 2018). A second finding that merits further investigation is the lack of awareness of the outcomes for male calves. Recent research has shown that high percentages of male dairy calves arrive with compromised health at calf-rearing facilities (Pempek et al., 2017; Renaud et al., 2018a), and this likely relates to their care on dairy farms (Renaud et al., 2018b). Studies looking at calf growth (Atkinson et al., 2017) and mastitis prevention (Jansen et al., 2010) suggest that when producers are aware of problems on their farm they can be motivated to change management strategies. This fits with the Health Belief Model (Rosenstock, 1974), a theory of behavioral change that acknowledges that decisions about whether to take action regarding an illness depend on the level of perceived risk. Further investigation could help clarify whether a lack of knowledge about male calf outcomes relates to suboptimal care on the dairy farm of origin.

Although a lack of clarity about calf care was an important barrier, the time and effort necessary to care for newborn calves were also viewed as barriers to the adoption of better management practices, especially for male calves. Mee (2013) suggested that the low prioritization of neonatal calf care was a major factor limiting calf survival. As well, although Sumner et al. (2018) concluded that participants in their study did value their calves, they noted that some producers did not highly prioritize calf health and productivity outcomes. Further evidence of the low prioritization of calves was found by Santman-Berends et al. (2014), who noted that producers in the Netherlands perceived that increased calf mortality in recent years related to farm industrialization, which required more care of the milking herd and left less time for calves. Danish producers who struggled with high calf mortality described a similar challenge with workload and had little "flexible time" to devote to calves (Vaarst and Sørensen, 2009). Our study provides evidence that low prioritization of calf care was particularly notable in male calves. Although improving overall farm labor efficiency to increase "flexible time" could be beneficial for all classes of animals, a change in producer mindset may be required to address the attitude that calves, and specifically male calves, are inherently lower-priority. Effective calf care must also achieve a balance among the needs of multiple classes of animals.

Beyond finding enough time and effort to devote to their calves, producers also noted that another barrier to optimal calf care was a lack of physical resources. This lack of resources included infrastructure challenges, which were highlighted by others as a barrier for producers in adopting milking hygiene practices (Belage et al., 2019) and controlling Johne's disease 
(Roche et al., 2019). In our study, producers commonly reported struggling with calf pneumonia associated with poor ventilation, even in new facilities. Infrastructure limitations highlight the need for further research into calf facility design, as well as increased investment in available technologies such as positive pressure tube ventilation (Nordlund and Halbach, 2019), which can improve air quality in existing infrastructure. Male calves were disproportionately affected by space limitations, compared with female calves; this has also been described as a limiting factor for converting pork and poultry farms to production systems that promote animal welfare (Gocsik et al., 2015). Producers frequently reported that weather limited calf care, emphasizing the importance of a thorough understanding of how to optimize facility performance in varying conditions.

A second limiting resource to providing good calf care was adequately trained staff. Farm owners expressed difficulty finding and training good employees, and employees noted that they received very little training in calf management when they were hired. In a study of employee management on US dairy farms, Durst et al. (2018) also found that minimal training was given to employees and suggested that increased investment in training could improve animal care and the job satisfaction of both employers and employees. Physical resource limitations may be addressed through knowledge translation (Belage et al., 2019), and Ritter et al. (2017) suggested that producers could be motivated to allocate available resources to issues they perceived to be urgent and solvable.

The economic context of the dairy industry was an important factor that acted as both a barrier and motivator for calf care in our study. The high costs associated with neonatal calf care were emphasized for male calves; some producers noted that the low selling price limited their care and in extreme cases resulted in calves being euthanized. Another producer viewed low prices differently and was motivated to provide good care to male calves to be able to sell them. A third subset of producers kept their male calves and felt that the cost of rearing them was worthwhile and contributed another revenue stream when they sold them as finished veal. These different perspectives were not surprising, because the importance placed on economic efficiency differs depending on producer characteristics (Jansen et al., 2010). As well, in reviewing reasons why producers adopt strategies to prevent and control disease, Ritter et al. (2017) concluded that cost-effectiveness is an important determinant, but that non-economic factors such as pride and job satisfaction are equally and potentially more influential.

Economic penalties or incentives could be used to influence the condition of male calves being sold, al- though employing this strategy would be difficult given the complex nature of male dairy calf marketing in the Canadian context (Wilson et al., 2020a). Several studies conducted in udder health have noted that economic strategies can be motivating; for example Valeeva et al. (2007) found that economic penalties were more motivating than incentives. Conversely, producers in a recent study on milking hygiene reported that they would be strongly motivated by price incentives (Belage et al., 2019). Alternatively, in our study, producers said that having consistent, baseline prices for their calves could motivate producers to provide good calf care. The use of economics to motivate improved calf care remains unclear, and successful strategies would likely require an interdisciplinary approach (Christensen et al., 2012).

Producers' intrinsic motivations, including pride and moral obligation, were important drivers of calf care in this study. McAloon et al. (2017) framed such motivations as values, and this type specifically as "cultural capital," which related to feelings of pride in actions associated with being a "good farmer." This sense of responsibility producers feel to provide good care for their animals has also been documented as an important motivator for mastitis management (Valeeva et al., 2007), transfer of passive immunity and growth in calves (Sumner et al., 2018), and Johne's disease prevention (Roche et al., 2019). These motivations extended to male calves; most producers expressed a desire for good outcomes for their calves, despite the likelihood of economic losses associated with rearing them. However, given the differences in care practices between male and female calves described by some producers, barriers such as prioritization of other classes of animals and physical resource limitations may have outweighed some of the internal motivation to provide male calves with optimal care.

Social expectations were an important extrinsic motivation influencing calf care. This finding was especially notable for male calves: producers reported that their care practices had implications for the public perception of the dairy industry. Producers are attuned to public opinion as shown in their perspectives on the prevention of Johne's disease. A lack of public outcry about Johne's disease acted as a deterrent in adopting prevention strategies for some producers, whereas others were more motivated because they perceived it to be a risk to the dairy industry (Roche et al., 2019). However, the drive to maintain the reputation of the dairy industry likely differs between producers and may be disease- or issue-specific; Valeeva et al. (2007) found it was only mildly important to producers in the Netherlands with respect to mastitis management. The social relationship between dairy producers and calf buyers or veal producers also influenced calf care: producers primarily 
expressed a desire to maintain a positive relationship with their calf buyer and raise calves that would go on to be successful under new management. Given the differing levels of care reported, the motivation generated by these social expectations may have again been weighed against other barriers, emotions, or philosophies related to calf care. Regardless, other researchers have advocated the use of social pressure to influence producers to change management practices related to udder health (Lam et al., 2011), and similar strategies could be used with producers who do not practice optimal male calf care.

Some frustration was expressed about the financial burden of recent regulations; however, producers described an overall positive influence of regulations on calf care. Specifically, regulations that limit the duration of transportation for cattle within different age categories (Canadian Food Inspection Agency, 2019) motivated producers to keep their male calves healthy. Similarly, Roche et al. (2019), found that producers felt that regulations about shipping milk from cows with Johne's disease would be necessary to control the disease. However, producers can also view regulations as unlikely to lead to positive change (Brennan et al., 2016) or "out of touch" with industry realities (Garforth et al., 2013). Some potential examples of minimum standards for male calves could include ensuring they receive colostrum, reach a minimum weight requirement, and have a healthy navel before sale; these have been among the most important determinants of subsequent poor health outcomes (Winder et al., 2016; Renaud et al., 2018a; Wilson et al., 2020b). Implementing these minimum standards for male dairy calves could be a role for government- or industry-led quality assurance programs such as the Canadian dairy industries nationwide program ProAction (DFC-PCL, 2019). The role of regulation in calf care practices will likely continue to be debated and to evolve, but in this context was viewed overall as a driver of positive practices.

The barriers and motivations that emerged in our analysis were informed by producers' sources of knowledge. Understanding how producers access information is important, because sufficient knowledge is critical for developing effective disease-mitigation strategies (Ritter et al., 2017). Producers said that they most commonly learned about calf care practices through personal experience, similar to pig producers, who described being "self-taught" (Garforth et al., 2013). Veterinarians were identified as an important information source on calf health, but other industry professionals also played a role on some farms. Similarly, veterinarians and nutritionists were important advisors for transition cow management on dairy farms (Mills et al., 2020), and veterinarians were reported as valuable resources regarding pig and sheep biosecurity (Garforth et al., 2013). Despite this, producers do not always think of veterinarians as calf advisors (Santman-Berends et al., 2014), and increased discussion between veterinarians and producers through benchmarking reports has been shown to enhance their perceived value as advisors (Sumner et al., 2020). The influence of external sources of knowledge likely depends on a producer's openness and the perceived trustworthiness of the information (Jansen et al., 2010). Another source of external information in the current study was communication with other producers, although few reported that it changed their practices. Similarly, Sumner et al. (2018) found that producers questioned whether other producers' calf practices would be feasible within the context of their farm. Our study suggests that experiential learning is most critical, but external sources of knowledge can also influence producers to adopt solutions for calf care challenges.

Potential limitations of this study were related to the recruitment of producers and possible hesitancy to discuss neonatal calf care. Focus group participants are selected purposively (Rabiee, 2004), in this case because they had applicable knowledge on the topic; participants are not meant to represent the larger population. In this instance, producers were all from Southern Ontario and represented larger farms than the average Ontario dairy farm, which has 94 lactating and dry cows (Canadian Dairy Information Centre, 2019). As well, the median age of producers was 32 y (21 to 59), younger than the average dairy producer in Ontario (50 y; Canadian Dairy Commission and Dairy Farmers of Ontario, 2019). These factors, combined with their willingness to participate in the focus groups, suggested that the dairy producers enrolled in this study may have a progressive attitude toward calf care. The reader should consider these and other contexts (e.g., economics of the Canadian dairy and veal industries) before determining if the results are generalizable to other populations. Given the potentially sensitive nature of the discussion, particularly related to the care of male dairy calves, producers may have also been hesitant to share their true views and practices because of a perceived need to provide socially acceptable answers (Polkinghorne, 2007). We addressed this limitation by using trained moderators who were not introduced as experts in calf care, establishing the confidentiality of the data and encouraging open sharing at the beginning of the focus group. The need to use 3 different moderators could also have affected the discussions, because the different styles could have elicited more or less openness among producers. However, this was unlikely, because themes were well represented across 
all groups and moderators were aware of the research goals and used a question guide.

This study was also limited to 4 focus groups based on the cancellation of social gatherings in response to the pandemic caused by COVID-19; we had intended to conduct 5 to 6 focus groups until saturation of data was reached based on the development of new codes (Hennink et al., 2019). However, similar to Hennink et al. (2019), we identified only 2 new codes in the 4 th focus group, suggesting that we had reached adequate data saturation. This number of focus groups was also deemed adequate based on the study objectives (describing themes broadly) and because we used a homogeneous population of dairy producers (Guest et al., 2006). Conducting additional focus groups with dairy producers from different regions or who were using nonconventional practices (e.g., organic dairy producers) could have revealed other perspectives. For example, a Canadian study recently noted differences related to region and farm size in the adoption of technology on dairy farms (Jelinski et al., 2020), so the importance of technology may have been emphasized with additional groups. Furthermore, emotional states were infrequently discussed because this was not an explicit research goal, but emotions could have a unique influence on calf care perspectives. Future studies could investigate how emotional state influences decisions about calf care practices.

\section{CONCLUSIONS}

The results of this study suggest that dairy producers in Ontario experience motivations and barriers related to their calf care practices that differ for male and female calves. A lack of clarity about the best management practices for calf care, the prioritization of farm resources to other classes of animals, and employee training were important limitations to calf care in general. Economic cost and infrastructure limitations were important considerations for the care of male calves and acted as a motivation or a barrier, depending on the context. Producers were motivated by their own morality along with social norms to provide good care to male calves. Sources of knowledge, individual beliefs, and emotions affected the level of care producers provided to their calves. Because of variations in motivations and barriers among producers, efforts to improve calf care should account for individual differences in producer perspectives.

\section{ACKNOWLEDGMENTS}

This work is supported by Agriculture \& Food Research Initiative Competitive Grant no. 2019-67015-
29574 from the USDA National Institute of Food and Agriculture (Washington, DC). We are grateful for the participation of the dairy producers in this study and for the veterinarians and the Dairy Farmers of Ontario for assistance with recruitment. The authors have not stated any conflicts of interest.

\section{REFERENCES}

Atkinson, D. J., M. A. G. von Keyserlingk, and D. M. Weary. 2017. Benchmarking passive transfer of immunity and growth in dairy calves. J. Dairy Sci. 100:3773-3782. https://doi.org/10.3168/jds .2016-11800.

Belage, E., S. L. Croyle, A. Jones-Bitton, S. Dufour, and D. F. Kelton. 2019. A qualitative study of Ontario dairy farmer attitudes and perceptions toward implementing recommended milking practices. J. Dairy Sci. 102:9548-9557. https://doi.org/10.3168/jds.2018 $-15677$.

Braun, V., and V. Clarke. 2006. Using thematic analysis in psychology. Qual. Res. Psychol. 3:77-101. https://doi.org/10.1191/ 1478088706qp063oa.

Brennan, M. L., N. Wright, W. Wapenaar, S. Jarratt, P. HobsonWest, I. F. Richens, J. Kaler, H. Buchanan, J. N. Huxley, and H. M. O'Connor. 2016. Exploring attitudes and beliefs towards implementing cattle disease prevention and control measures: A qualitative study with dairy farmers in Great Britain. Animals (Basel) 6:61. https://doi.org/10.3390/ani6100061.

Bruijnis, M., H. Hogeveen, C. Garforth, and E. Stassen. 2013. Dairy farmers' attitudes and intentions towards improving dairy cow foot health. Livest. Sci. 155:103-113. https://doi.org/10.1016/j.livsci .2013.04.005.

Canadian Dairy Commission and Dairy Farmers of Ontario. 2019. Ontario dairy farm accounting project. Accessed Jun. 6, 2020. https:/ /milk.org/corporate/pdf/Publications-ODFAPReport.pdf.

Canadian Dairy Information Centre. 2019. Number of farms, dairy cows and dairy heifers. Accessed Jun. 2, 2020. https://www.dairyinfo.gc .ca/eng/dairy-statistics-and-market-information/farm-statistics/ farms-dairy-cows-and-dairy-heifers $/ ? \mathrm{id}=1502467423238$.

Canadian Food Inspection Agency. 2019. Regulations amending the health of animals regulations. Can. Gaz., II 153:47-115.

Cardwell, J. M., S. Van Winden, W. Beauvais, A. Mastin, W. A. De Glanville, J. Hardstaff, R. E. Booth, J. Fishwick, and D. U. Pfeiffer. 2016. Assessing the impact of tailored biosecurity advice on farmer behaviour and pathogen presence in beef herds in England and Wales. Prev. Vet. Med. 135:9-16. https://doi.org/10.1016/j .prevetmed.2016.10.018.

Christensen, T., A. Lawrence, M. Lund, A. Stott, and P. Sandøe. 2012. How can economists help to improve animal welfare? Anim. Welf. 21:1-10. https://doi.org/10.7120/096272812X13345905673449.

Croyle, S. L., E. Belage, D. K. Khosa, S. J. LeBlanc, D. B. Haley, and D. F. Kelton. 2019. Dairy farmers' expectations and receptivity regarding animal welfare advice: A focus group study. J. Dairy Sci. 102:7385-7397. https://doi.org/10.3168/jds.2018-15821.

DFC-PCL. 2019. ProAction: On-Farm Excellence. Accessed May 7, 2019. https://www.dairyfarmers.ca/proaction.

Durst, P. T., S. J. Moore, C. Ritter, and H. W. Barkema. 2018. Evaluation by employees of employee management on large US dairy farms. J. Dairy Sci. 101:7450-7462. https://doi.org/10.3168/jds .2018-14592.

Fecteau, G., P. Baillargeon, R. Higgins, J. Paré, and M. Fortin. 2002. Bacterial contamination of colostrum fed to newborn calves in Québec dairy herds. Can. Vet. J. 43:523-527.

Fordyce, A. L., L. L. Timms, K. J. Stalder, and H. D. Tyler. 2018. Short communication: The effect of novel antiseptic compounds on umbilical cord healing and incidence of infection in dairy calves. J. Dairy Sci. 101:5444-5448. https://doi.org/10.3168/jds.2017-13181.

Garforth, C. J., A. P. Bailey, and R. B. Tranter. 2013. Farmers' attitudes to disease risk management in England: A comparative 
analysis of sheep and pig farmers. Prev. Vet. Med. 110:456-466. https://doi.org/10.1016/j.prevetmed.2013.02.018.

Gocsik, É., I. A. van der Lans, A. G. J. M. O. Lansink, and H. W. Saatkamp. 2015. Willingness of Dutch broiler and pig farmers to convert to production systems with improved welfare. Anim. Welf. 24:211-222. https://doi.org/10.7120/09627286.24.2.211.

Guest, G., A. Bunce, and L. Johnson. 2006. How many interviews are enough? An experiment with data saturation and variability. Field Methods 18:59-82. https://doi.org/10.1177/1525822X05279903.

Hennink, M. M., B. N. Kaiser, and M. B. Weber. 2019. What influences saturation? Estimating sample sizes in focus group research. Qual. Health Res. 29:1483-1496. https://doi.org/10.1177/ 1049732318821692.

Jansen, J., C. D. M. Steuten, R. J. Renes, N. Aarts, and T. J. G. M. Lam. 2010. Debunking the myth of the hard-to-reach farmer: Effective communication on udder health. J. Dairy Sci. 93:12961306. https://doi.org/10.3168/jds.2009-2794.

Jelinski, M. D., D. F. Kelton, C. Luby, and C. L. Waldner. 2020. Factors associated with the adoption of technologies by the Canadian dairy industry. Can. Vet. J. 61:1065-1072.

Krueger, R. A., and M. A. Casey. 2000. Focus Groups: A Practical Guide for Applied Research. Sage Publications.

Lam, T. J. G. M., J. Jansen, B. H. P. van den Borne, R. Renes, and H. Hogeveen. 2011. What veterinarians need to know about communication to optimise their role as advisors on udder health in dairy herds. N. Z. Vet. J. 59:8-15. https://doi.org/10.1080/00480169 .2011.547163.

Lava, M., G. Schüpbach-Regula, A. Steiner, and M. Meylan. 2016. Antimicrobial drug use and risk factors associated with treatment incidence and mortality in Swiss veal calves reared under improved welfare conditions. Prev. Vet. Med. 126:121-130. https://doi.org/ 10.1016/j.prevetmed.2016.02.002.

Marquou, S., L. Blouin, H. Djakite, R. Laplante, and S. Buczinski. 2019. Health parameters and their association with price in young calves sold at auction for veal operations in Québec, Canada. J. Dairy Sci. 102:6454-6465. https://doi.org/10.3168/jds.2018-16051.

McAloon, C. G., Á. Macken-Walsh, L. Moran, P. Whyte, S. J. More, L. O'Grady, and M. L. Doherty. 2017. Johne's disease in the eyes of Irish cattle farmers: A qualitative narrative research approach to understanding implications for disease management. Prev. Vet. Med. 141:7-13. https://doi.org/10.1016/j.prevetmed.2017.04.001.

McDonald, N., S. Schoenebeck, and A. Forte. 2019. Reliability and inter-rater reliability in qualitative research: Norms and guidelines for CSCW and HCI practice. Proc. ACM Human-Computer Interact. 3:72. https://doi.org/doi:10.1145/3359174.

Mee, J. F. 2013. Why do so many calves die on modern dairy farms and what can we do about calf welfare in the future? Animals (Basel) 3:1036-1057. https://doi.org/10.3390/ani3041036.

Mills, K. E., D. M. Weary, and M. A. G. von Keyserlingk. 2020. Identifying barriers to successful dairy cow transition management. J. Dairy Sci. 103:1749-1758. https://doi.org/10.3168/jds.2018-16231.

Nordlund, K. V., and C. E. Halbach. 2019. Calf barn design to optimize health and ease of management. Vet. Clin. North Am. Food Anim. Pract. 35:29-45. https://doi.org/10.1016/j.cvfa.2018.10 .002 .

O'Brien, B. C., I. B. Harris, T. J. Beckman, D. A. Reed, and D. A. Cook. 2014. Standards for reporting qualitative research: A synthesis of recommendations. Acad. Med. 89:1245-1251. https://doi .org/10.1097/ACM.0000000000000388.

Pardon, B., K. De Bleecker, M. Hostens, J. Callens, J. Dewulf, and P. Deprez. 2012. Longitudinal study on morbidity and mortality in white veal calves in Belgium. BMC Vet. Res. 8:26. https://doi.org/ 10.1186/1746-6148-8-26.

Pempek, J., D. Trearchis, M. Masterson, G. Habing, and K. Proudfoot. 2017. Veal calf health on the day of arrival at growers in Ohio. J. Anim. Sci. 95:3863-3872. https://doi.org/10.2527/jas2017 .1642.

Polkinghorne, D.E. 2007. Validity issues in narrative research. Qual. Inquiry 13:471-486. https://doi.org/10.1177/1077800406297670.

Rabiee, F. 2004. Focus-group interview and data analysis. Proc. Nutr. Sci. 63:655-660. https://doi.org/10.1079/PNS2004399.
Renaud, D. L., T. F. Duffield, S. J. LeBlanc, D. B. Haley, and D. F. Kelton. 2017. Management practices for male calves on Canadian dairy farms. J. Dairy Sci. 100:6862-6871. https://doi.org/10.3168/ jds.2017-12750.

Renaud, D. L., T. F. Duffield, S. J. LeBlanc, D. B. Haley, and D. F. Kelton. 2018a. Clinical and metabolic indicators associated with early mortality at a milk-fed veal facility: A prospective case-control study. J. Dairy Sci. 101:2669-2678. https://doi.org/10.3168/ jds.2017-14042.

Renaud, D. L., D. F. Kelton, S. J. LeBlanc, D. B. Haley, and T. F. Duffield. 2018b. Calf management risk factors on dairy farms associated with male calf mortality on veal farms. J. Dairy Sci. 101:1785-1794. https://doi.org/10.3168/jds.2017-13578.

Renaud, D. L., M. W. Overton, D. F. Kelton, S. J. Leblanc, K. C. Dhuyvetter, and T. F. Duffield. 2018c. Effect of health status evaluated at arrival on growth in milk-fed veal calves: A prospective single cohort study. J. Dairy Sci. 101:10383-10390. https://doi .org/10.3168/jds.2018-14960.

Renaud, D. L., K. M. Waalderbos, L. Beavers, T. F. Duffield, K. E. Leslie, and M. C. Windeyer. 2020. Risk factors associated with failed transfer of passive immunity in male and female dairy calves: A 2008 retrospective cross-sectional study. J. Dairy Sci. 103:35213528. https://doi.org/10.3168/jds.2019-17397.

Ritter, C., J. Jansen, S. Roche, D. F. Kelton, C. L. Adams, K. Orsel, R. J. Erskine, G. Benedictus, T. J. G. M. Lam, and H. W. Barkema. 2017. Invited review: Determinants of farmers' adoption of management-based strategies for infectious disease prevention and control. J. Dairy Sci. 100:3329-3347. https://doi.org/10.3168/ jds.2016-11977.

Roche, S. M., D. F. Kelton, M. Meehan, M. Von Massow, and A. JonesBitton. 2019. Exploring dairy producer and veterinarian perceptions of barriers and motivators to adopting on-farm management practices for Johne's disease control in Ontario, Canada. J. Dairy Sci. 102:4476-4488. https://doi.org/10.3168/jds.2018-15944.

Rosenstock, I. M. 1974. Historical origins of the health belief model. Health Educ. Monogr. 2:328-335. https://doi.org/10.1177/ 109019817400200403

Santman-Berends, I. M. G. A., M. Buddiger, A. J. G. Smolenaars, C. D. M. Steuten, C. A. J. Roos, A. J. M. Van Erp, and G. Van Schaik. 2014. A multidisciplinary approach to determine factors associated with calf rearing practices and calf mortality in dairy herds. Prev. Vet. Med. 117:375-387. https://doi.org/10.1016/j .prevetmed.2014.07.011.

Shivley, C. B., J. E. Lombard, N. J. Urie, D. M. Weary, and M. A. G. von Keyserlingk. 2019. Management of preweaned bull calves on dairy operations in the United States. J. Dairy Sci. 102:4489-4497. https://doi.org/10.3168/jds.2018-15100.

Sumner, C. L., and M. A. G. von Keyserlingk. 2018. Canadian dairy cattle veterinarian perspectives on calf welfare. J. Dairy Sci. 101:10303-10316. https://doi.org/10.3168/jds.2018-14859.

Sumner, C. L., M. A. G. von Keyserlingk, and D. M. Weary. 2018. How benchmarking motivates farmers to improve dairy calf management. J. Dairy Sci. 101:3323-3333. https://doi.org/10.3168/jds .2017-13596.

Sumner, C. L., M. A. G. von Keyserlingk, and D. M. Weary. 2020. How benchmarking promotes farmer and veterinarian cooperation to improve calf welfare. J. Dairy Sci. 103:702-713. https://doi.org/ 10.3168/jds.2019-16338.

Vaarst, M., and J. T. Sørensen. 2009. Danish dairy farmers' perceptions and attitudes related to calf-management in situations of high versus no calf mortality. Prev. Vet. Med. 89:128-133. https:/ /doi.org/10.1016/j.prevetmed.2009.02.015.

Valeeva, N. I., T. J. G. M. Lam, and H. Hogeveen. 2007. Motivation of dairy farmers to improve mastitis management. J. Dairy Sci. 90:4466-4477. https://doi.org/10.3168/jds.2007-0095.

Veal Farmers of Ontario. 2020. Weekly market information report. Accessed Nov. 20, 2020. https://vealfarmers.ca/wp-content/uploads/ 2020/02/VFO-Market-Report-2020.02.28.pdf.

Wieland, M., S. Mann, C. L. Guard, and D. V. Nydam. 2017. The influence of 3 different navel dips on calf health, growth performance, and umbilical infection assessed by clinical and ultrasono- 
graphic examination. J. Dairy Sci. 100:513-524. https://doi.org/ 10.3168/jds.2016-11654.

Wilson, D. J., D. Canning, T. Giacomazzi, K. Keels, R. Lothrop, D.L. Renaud, N. Sillett, D. Taylor, H. Van Huigenbos, B. Wynands, D. Zuest, and D. Fraser. 2020a. Hot Topic: Health and welfare challenges in the marketing of male dairy calves-Findings and consensus of an expert consultation. J. Dairy Sci. 103:11628-11635. https://doi.org/10.3168/jds.2020-18438.

Wilson, D. J., J. Stojkov, D. L. Renaud, and D. Fraser. 2020b. Risk factors for poor health outcomes for male dairy calves undergoing transportation in Western Canada. Can. Vet. J. 61:1265-1272.

Wilson, D. J., J. Stojkov, D. L. Renaud, and D. Fraser. 2020c. Short communication: Condition of male dairy calves at auction markets. J. Dairy Sci. 103:8530-8534. https://doi.org/10.3168/jds 2019-17860.

Winder, C. B., D. F. Kelton, and T. F. Duffield. 2016. Mortality risk factors for calves entering a multi-location white veal farm in Ontario, Canada. J. Dairy Sci. 99:10174-10181. https://doi.org/10 $.3168 /$ jds.2016-11345.

Windeyer, M. C., K. E. Leslie, S. M. Godden, D. C. Hodgins, K. D. Lissemore, and S. J. LeBlanc. 2014. Factors associated with morbidity, mortality, and growth of dairy heifer calves up to 3 months of age. Prev. Vet. Med. 113:231-240. https://doi.org/10.1016/j .prevetmed.2013.10.019.

\section{ORCIDS}

Devon J. Wilson ๑ https://orcid.org/0000-0001-8027-7998 Jessica A. Pempek @ \ttps://orcid.org/0000-0002-5977-2086 Katherine C. Creutzinger () https://orcid.org/0000-0002-6237-5145 Gregory Habing @ https://orcid.org/0000-0002-0855-7650 Kathryn L. Proudfoot (ํ) https://orcid.org/0000-0001-5877-2431 Kelly A. George @ \ttps://orcid.org/0000-0002-2576-8564 David L. Renaud @ https://orcid.org/0000-0002-3439-3987

\section{APPENDIX 1}

\section{Discussion Guide}

\section{Introduction and Icebreaker}

Section I: Opening Question and Employee Training. Tell us about newborn calf care on your farm.

Follow-up: Can you tell us a little bit about how calf caretakers are trained to take care of newborn calves?

Follow-up: Do you have the same caretaker for heifer and bull calves?

o Probe: Are there any differences in the way they are trained to care for heifer and bull calves?

Section II: Colostrum Management. Please describe colostrum management on your operation.

Follow-up: Are there any differences in colostrum management between heifer and bull calves? [Probe as relevant, and make sure to discuss each item below.]

o Feeding method (i.e., suckling, tubed, bottle, bucket) o Quality

o Quantity

o Timing

o Number of colostrum feedings

o Other

o Probe: Can you elaborate on the advantages or disadvantages of having different colostrum protocols for heifer and bull calves?

Section III: Navel Care. Please tell us about your navel care protocol.

Follow-up: Is your navel care protocol the same for heifers and bulls?

o Probe: Can you elaborate on the advantages or disadvantages of having different navel care protocols for heifer and bull calves?

Section IV: Milk Feeding. Tell us about milkfeeding practices for calves on your farm for the first couple weeks of life.

$\square$ Follow-up: Is this protocol the same for heifer and bull calves? Please elaborate on the potential differences.

Section V: General Newborn Management. In your opinion, what aspects do you consider the most important for newborn calf care? Please elaborate on why. [Probe potential differences for heifers and bulls.]

What are the biggest challenges you face with regard to newborn calf care? Do these challenges differ between bull and heifer calves?

$\square$ Follow-up: What would help you overcome those challenges?

Section VI: Sale of Male Calves. When do bull calves typically leave your operation?

Follow-up: What do you do to prepare the calves before they leave the farm (e.g., vaccination, feed/water directly before sale, etc.)?

Follow-up: If a calf is sick, how might this influence how you prepare them? [Probe for antibiotic treatment, delayed sale.]

Follow-up: If a calf needs an antibiotic, what factors do you consider before treatment?

o Probe: Are these factors or protocols similar for heifer and bull calves? Please elaborate on the potential differences.

Where do you typically sell your bull calves (e.g., through auction, another local farm, harvest), and why? [Probe for price, consistent pick up of bulls/ transportation, etc.]

Do you have a preference for their final destination (e.g., bob veal, veal harvested at 6 mo, dairy beef)? Can you elaborate on why you prefer that destination?

Final Question. Overall, what is your perception of the value of bull calves? 


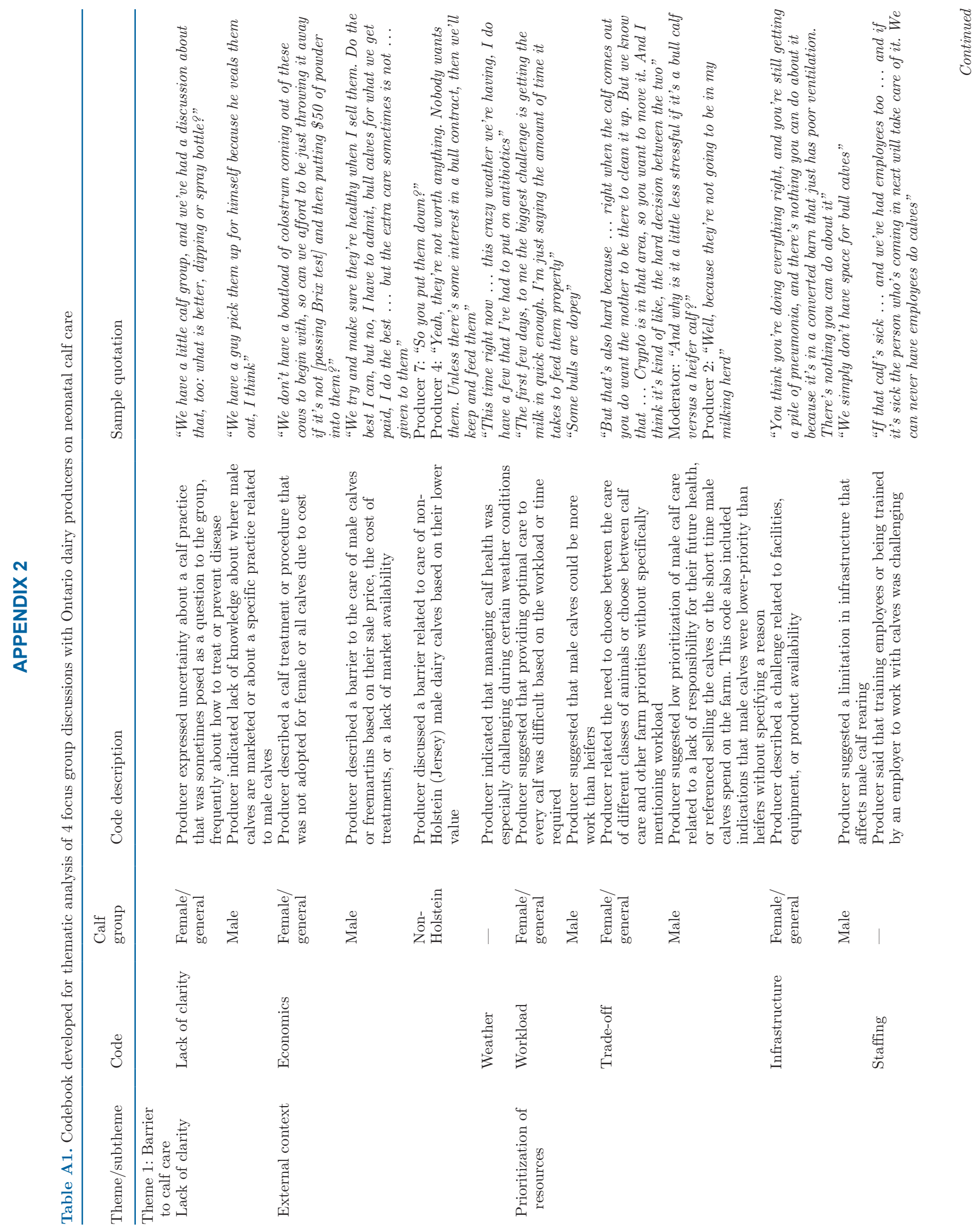




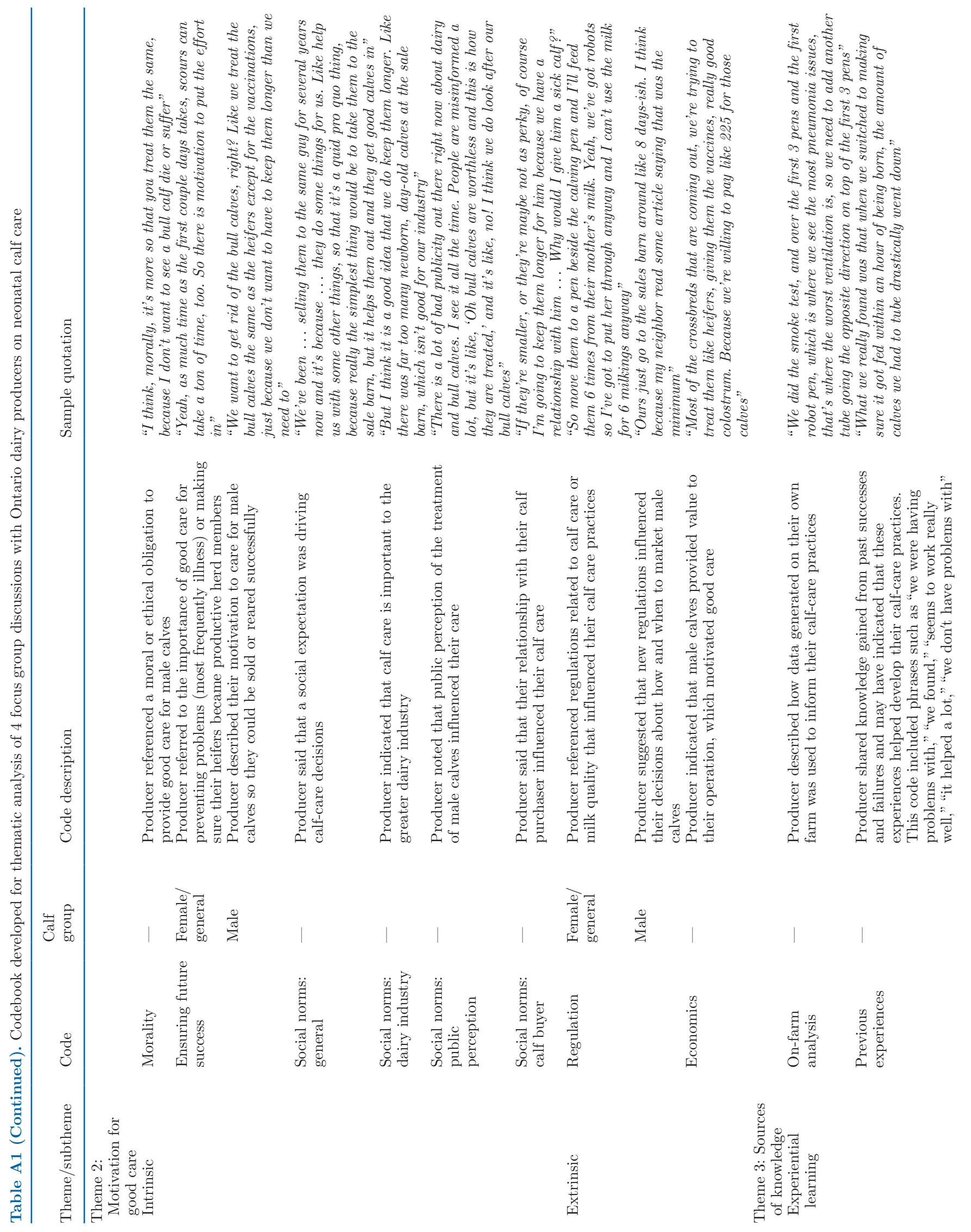




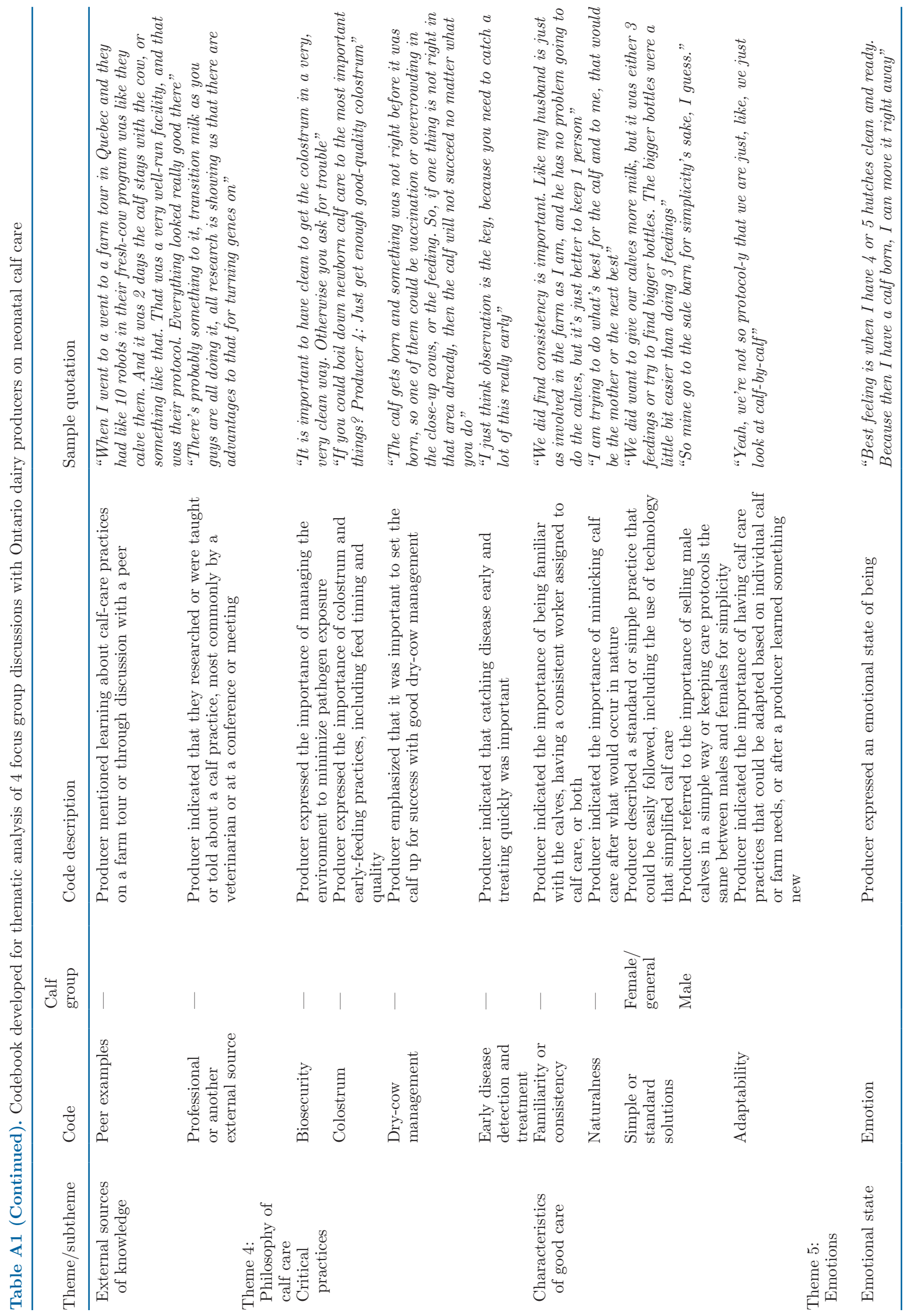

